\title{
Fluoxetine in the management of Major Depressive Disorder in Children and Adolescents: A meta-analysis of Randomized Controlled Trials
}

Ayman Antoun Reyad ${ }^{1}$, Kiran Plaha $^{2}$, Eriny Girgis $^{3}$ and Raafat Mishriky ${ }^{3}$

${ }^{1}$ Senior lecturer in Pharmacology, School of Pharmacy, University of

Wolverhampton, WV1 1LY, Wolverhampton, UK

${ }^{2}$ School of Pharmacy, University of Wolverhampton, WV1 1LY, Wolverhampton,

UK

${ }^{3}$ Dental officer, Community Dental Service, City of Coventry Health Centre,

Coventry and Warwickshire Partnership NHS trust, CV1 4FS

${ }^{4}$ Consultant in Old Age Psychiatry, Birmingham and Solihull Mental Health NHS

Foundation Trust, Honorary Senior Lecturer in Old Age Psychiatry, Aston Medical

School, Aston University, Birmingham, UK

Email: a.antounreyad@wlv.ac.uk

Tel: 00441902322291

Running title: Fluoxetine in Major Depressive Disorder

Keywords: Fluoxetine, Major Depressive Disorder, Psychiatric Disorders, Children and adolescent, Mental Health, Children's depression rating Scale 


\section{Abstract}

Fluoxetine is a serotonin specific reuptake inhibitor anti-depressant and is the only approved pharmacological treatment for major depressive disorder (MDD) in children and adolescent. We searched the published randomized controlled-trials $(\mathrm{RCT})$ to review fluoxetine efficacy and tolerability using the databases PubMed, EUDRACT, ClinicalTrials.gov and Cochrane Central Register of Controlled Trials for fluoxetine role in managing MDD in children and adolescents. A meta-analysis was conducted using the identified 7 clinical trials to assess efficacy using the outcomes: Children's Depression Rating Scale-Revised (CDRS-R), Clinical Global Impressions - Severity of IIIness (CGI-S) and Clinical Global Impressions Improvement (CGI-I) response rate. The risk of discontinuation due to adverse effects and common side effects were examined. The mean difference in change from baseline for CDRS-R was -2.72 [95\% Confidence Interval (CI) -3.96, -1.48] favouring fluoxetine treatment $(p<0.001)$. Similarly, mean difference for CGI-S was $-0.21[95 \% \mathrm{Cl}-0.36,-0.06]$. The risk ratio $(\mathrm{RR})$ of discontinuing due to adverse events was 0.98 [95\% Cl 0.54, 1.83], with RR for headache side effects 1.34 [95\% Cl 1.03, 1.74] and rash $2.6[95 \% \mathrm{Cl} 1.32,5.14]$. Fluoxetine demonstrates significant improvements in symptom intensity control in young patients suffering from MDD and is considered well-tolerated with similar rates of trials discontinuation; however, fluoxetine was associated with a higher risk of headache and rash side effects. These findings will guide psychiatrists and pharmacists in their clinical role for supporting the care of young mental health patients. 


\section{Introduction}

Depression is characterised by low mood and loss of pleasure ${ }^{1}$ with symptoms including reduced concentration, feeling of guilt, negative thoughts and disturbed sleep ${ }^{2}$. According to DSM- $5^{3}$, individuals must be experiencing five or more symptoms (depressed mood, diminished interest or pleasure, significant weight loss, slowing down of thought and a reduction of physical movement, fatigue, feelings of worthlessness or excessive or inappropriate guilt, diminished ability to think or concentrate and recurrent suicidal ideation) during 2-week period with at least either depressed mood or loss of interest/pleasure as a core symptom ${ }^{4}$. Worldwide, over 260 million suffer from depressive disorders - a main cause of disability - leading to difficulties in social functioning and suicide ${ }^{5}$. In children and adolescents, depression increased incidence of alcohol consumption, drug use and self-harm ${ }^{6}$. Alcohol abuse has been shown to decrease serotonin levels leading to deteriorating of the depressive symptoms and increased suicide incidence ${ }^{7}$. For a diagnosis of depression to be made, the patient must have experienced symptoms for most of the day for 2 weeks ${ }^{1}$, while International Statistical Classification of Diseases (ICD-10) classifies depression into three main categories: mild, moderate and severe. Depression in adults is diagnosed using psychiatric scales such as Beck Depression Inventory (BDI), while clinician rated scale such as Children's Depression Rating Scale -Revised (CDRS-R) are used for children/adolescents ${ }^{8}$.

A variety of antidepressants have shown efficacy in depression management in adults, including tricyclic antidepressants (TCAs), selective serotonin re-uptake inhibitors (SSRIs), serotonin and noradrenaline re-uptake inhibitors (SNRIs) and monoamine oxidase inhibitors (MAOIs) ${ }^{9}$. In contrast, few studies have been 
conducted in young people, where it is recommended that pharmacological therapy is initiated once psychological treatment is in use. SSRIs are the first-line pharmacological therapy in young people and currently, fluoxetine is the only licensed anti-depressant for adolescents in the UK ${ }^{1}$. On the other hand, there are some concerns regarding association of SSRI with suicide incidence in children and adolescents ${ }^{10-12}$.

SSRls inhibit the neurotransmitter 5-hydroxytryptamine (serotonin) reuptake into serotoninergic neurones, leading to increased serotonin level in the synapse. Compared to TCAs, SSRI cause less anticholinergic side effects and are safer in overdose ${ }^{9}$. SSRI are also indicated for the management of co-morbid anxiety and obsessive-compulsive disorder (OCD) ${ }^{9}$. Fluoxetine is relatively long-acting with a half-life of 1 - 3 days, which could increase further to 4 to 6 days following chronic administration ${ }^{13}$ and is extensively sequestered in tissues ${ }^{14}$. Fluoxetine is mainly metabolised via the CYP2D6 pathway in the liver to the active metabolite norfluoxetine (half-life $\sim 9$ days) ${ }^{13}$. The aim of the systematic meta-analysis is to update knowledge regarding fluoxetine efficacy and safety compared to placebo in children and adolescents diagnosed with MDD.

\section{Methods}

\section{Search strategy}

The focussed research question: "Will fluoxetine compared with placebo lower the severity of depression and alter adverse effects' incidence in children and adolescents with MDD".

The study population included children and adolescent patients taking part in RCT's assigned to either fluoxetine or placebo for the management of MDD. A literature search was performed for RCT's investigating the efficacy and/or safety of 
fluoxetine compared to placebo. The search terms 'fluoxetine, placebo, major depressive disorders' were used in PubMed, ScienceDirect, EUDRACT, ClinicalTrials.gov and Cochrane Central Register of Controlled Trials up to September 2019 with filters applied such as 'clinical trials' and 'child/adolescents'. No restrictions on study size, year of study or duration were set. Titles were screened for relevance, duplicates removed, then abstracts screened before the remaining relevant full texts were examined to find those meeting the inclusion criteria (Figure 1).

\section{Efficacy and Tolerability Outcomes}

The primary efficacy outcomes of included RCT were measured using self-report or clinician-rated scales, where generally, clinician-rated scales are more reliable. One of the most commonly used scales was CDRS-R, a clinician-rated scale used to measure the severity of depression ${ }^{15}$, which contains 17 items in total, 14 of which were rated from 1 to 7 with the remaining 3 rated from 1 to 5 with a total score can range from $17-113^{8}$. Clinical Global Impressions-Severity of IIIness Score (CGI-S), a clinician rated scale, was also used for depressive symptoms severity ${ }^{16}$. The primary tolerability and safety outcomes for fluoxetine were discontinuation due to adverse effects and side effects.

Statistical analysis

Review Manager 5.3 (RevMan) along with the Cochrane Collaboration tool for assessing the risk of bias 17,18 were used to assess the levels of selection, performance, detection, attrition and reporting bias in each of the chosen RCT's. 'Characteristics of study' tables were completed in RevMan for each of the individual studies and a summary table was created ${ }^{18}$. 
The inverse variance method with fixed effects model was used to calculate the mean differences for continuous outcomes. The Mantel-Haenszel method with random effects model used to calculate the risk ratio for dichotomous outcomes (Risk of discontinuation due to adverse effects and side effects) ${ }^{19}$ using RevMan, $95 \%$ confidence intervals was determined. $p$-value $<0.05$ was regarded as statistically significant ${ }^{18}$. Variations can occur between trials as they will differ in aspects such as participants, interventions and outcomes ${ }^{20}$, thus, a test for heterogeneity was carried out using chi-squared $\left(\mathrm{Chi}^{2}\right)$ test and $\mathrm{I}^{2}$ value.

\section{Results}

\section{Search results and included studies}

Figure 1 shows the selection process of included RCT's. PubMed, EUDRACT, ClinicalTrials.gov and Cochrane Central Register of Controlled Trials were searched for 'Fluoxetine' giving 2441 records in total. After removing duplicates and screening titles and abstracts, 24 studies were included in full text screening, while 7 RCTs met the inclusion criteria ${ }^{21-27}$. Table 1 shows the characteristics of the included published randomized controlled trials that investigated the tolerability, safety or efficacy of fluoxetine in patients suffering from MDD, a total of 1259 patients were included in the studies analysed within this review. All RCTs were double blinded and placebo-controlled with treatment duration range 6 to 10 weeks. Studies were undertaken in regions including USA, Russia with similar prevalence and incidence rates to the UK ${ }^{28}$. Trials containing serious co-morbidities, including diagnosis of other DSM-IV defined disorders such as bipolar disorder, psychotic depression or substance abuse disorder were excluded.

Figure 2 shows the risk of bias with the sequence generation, allocation concealment and blinding mostly with 'unclear' risk due to insufficient information. 
The patients in all the studies were randomly assigned and there was certain level of blinding for both participants and personnel. The domains relating to the completeness of data and reporting of outcomes were 'low' risk of bias, while other risks were high due to the high extent of trials funding/support by pharmaceutical companies (Figure 2).

\section{Efficacy of Fluoxetine in Children and Adolescents Major Depressive Disorders}

The mean change from baseline in CDRS-R was -2.72 [95\% Confidence Interval (Cl) $-3.96,-1.48$ ] favouring fluoxetine treatment $(p<0.001)$, with a total of 601 fluoxetine patients and 592 placebo patients included in the analysis (Figure 3a). The forest plot shows the MD for all the studies individually favor fluoxetine with some degree of heterogeneity between the studies $\left(x^{2}=16.52, I^{2}=70 \%\right)$. The mean difference (MD) for CGI-S was -0.21 with $95 \% \mathrm{Cl}-0.36$ to -0.06 (Figure $3 \mathrm{~b}$ ) favoring fluoxetine. Atkinson show data not consistent with the other trials regarding CGI-S, with high heterogeneity between the studies $\left(x^{2}=17.81, I^{2}=78 \%\right)$. CGI response rate was higher in fluoxetine compared to placebo, with a risk ratio $(R R)=1.46[1.27$ to 1.67] (Figure 3c) and moderate heterogeneity between trials $\left(x^{2}=4.36, I^{2}=31 \%\right)$.

Only two RCTs ${ }^{23,24}$ measured the effect of fluoxetine on CDRS mood, somatic and behaviour subscales (Figure 3d, 3e and 3f) with the overall result showed a positive effect for fluoxetine on all three subscales with MD from baseline $-2.65[95 \% \mathrm{Cl}$ $3.77,-1.52$ ], -2.48 [95\% $\mathrm{Cl}-3.61,-1.34$ ], -1.77 [95\% Cl -2.6, -0.94] respectively with low to moderate heterogeneity among the studies.

Tolerability and Safety of Fluoxetine in Children and Adolescents Major Depressive Disorders 
The overall risk ratio for trial discontinuation due to adverse effects is 0.99 [0.54 to 1.83], $p=0.98$, showing no major differences between fluoxetine and placebo groups (Figure 4a), with some variation among the studies with some favouring fluoxetine, and others favouring placebo $\left(\mathrm{I}^{2}=12 \%\right)$. There was no significant statistical difference in the total incidence of side effects between fluoxetine and placebo $(p=0.52)$ (Figure $4 b)$. Fluoxetine was associated with some mild side effects including headache $R R=1.34$ [1.03 to 1.74], $p=0.03$ and rash $R R=2.60$ [1.32 to 5.14], $p=0.006$ (Figure 4). For the other side effects such as suicidal ideation, dizziness, sedation, nausea and vomiting, no significant statistical differences were detected between fluoxetine and placebo.

\section{Discussion and Conclusion}

This systematic review/meta-analysis investigated the efficacy and safety of fluoxetine for the management of MDD in children and adolescents using the available clinical trials. Fluoxetine improved CDRS-R total psychiatric scale used for measuring symptom severity in young patients with depression. Fluoxetine also showed significant improvements in CGI-S and CGI-I response rate. This metaanalysis update knowledge regarding the role of fluoxetine as it is currently, the only antidepressant licensed for use in children and adolescents. These results are consistent with a previous meta-analysis that showed fluoxetine and escitalopram the only treatments with possible efficacy as anti-depressants in children and adolescents ${ }^{29}$. These results (Figure 3) confirmed the efficacy of fluoxetine as highlighted in other meta-analyses covering several antidepressants and showing a moderate beneficial role of fluoxetine in MDD ${ }^{30,31}$. Another meta-analysis casted doubt on the role of fluoxetine in MDD in children and adolescents ${ }^{32}$; however, new data included from recent trials are included in this article supports fluoxetine 
efficacy. Risk of discontinuing was similar in fluoxetine compared to placebo with equal risk of total side effects in the fluoxetine treatment compared to placebo.

These results confirm that there were insignificant changes in treatment emergent suicidal thoughts with fluoxetine, in agreement with previous research ${ }^{29}$. Generally, these findings focused on fluoxetine as anti-depressant in the management of MDD supported and updated other researchers' work ${ }^{33}$ that showed efficacy consistent with these findings even in adults ${ }^{34}$. Furthermore, these findings showed fluoxetine efficacy as a pharmacological treatment of MDD in children and adolescents ${ }^{35}$, while including a recent large scale clinical trial ${ }^{27}$. Results (Figure 4) also show that fluoxetine was associated with mild side effects such as headache $(R R=1.34)$ and Rash $(R R=2.6)$. This review shows that fluoxetine is well tolerated and significantly improves MDD in children and adolescents. The results need to be interpreted with caution as the treatment length ranged from just 6 to 10 weeks, with not enough evidence for long-term treatment effects, while several doses of fluoxetine were used with different efficacy and side effects profile. Therefore, it is recommended that further research using different doses with long-term treatment is conducted for a more comprehensive understanding of the role of fluoxetine in the management of MDD.

This research received no specific grant from any funding agency in the public, commercial, or not-for-profit sectors.

\section{Conflicts of interest}

'The Author(s) declare(s) that there is no conflict of interest'. 


\section{References}

1. National Institute for Health and Care excellence, NICE. Depression in children and young people: Identification and management NICE guideline [NG134]. 2019; .

2. Witkin JM, Li X. New approaches to the pharmacological management of major depressive disorder. Adv Pharmacol. 2009; 57:347-379.

3. American Psychiatric Association. Diagnostic and Statistical Manual of Mental Disorders (DSM-5). 5th ed. American Psychiatric Association Publishing, 2013.

4. Psycom. Depression Definition and DSM-5 Diagnostic Criteria $<$ https://www.psycom.net/depression-definition-dsm-5-diagnosticcriteria/\#dsm-5diagnosticcriteria>. Accessed 31.03. 2020.

5. GBD 2017 Disease and Injury Incidence and Prevalence Collaborators. Global, regional, and national incidence, prevalence, and years lived with disability for 354 diseases and injuries for 195 countries and territories, 19902017: A systematic analysis for the global burden of disease study 2017. Lancet. 2018; 392:1789-1858.

6. Kelvin R. Depression in children and young people. Paediatrics and Child Health. 2016; 26:540-547.

7. Groves SA, Stanley BH, Sher L. Ethnicity and the relationship between adolescent alcohol use and suicidal behavior. Int J Adolesc Med Health. 2007; 19:19-25. 
8. Brooks SJ, Kutcher S. Diagnosis and measurement of adolescent depression: A review of commonly utilized instruments. J Child Adolesc Psychopharmacol. 2001; 11:341-376.

9. Rang H, Ritter J, Flower R, Henderson G. Rang \& Dale's Pharmacology. 8th ed. ElSevier Churchill Livingston, 2016.

10. Wong IC, Besag FM, Santosh PJ, Murray ML. Use of selective serotonin reuptake inhibitors in children and adolescents. Drug Saf. 2004; 27:991-1000.

11. Murray ML, Thompson M, Santosh PJ, Wong IC. Effects of the committee on safety of medicines advice on antidepressant prescribing to children and adolescents in the UK. Drug Saf. 2005; 28:1151-1157.

12. Newman TB. A black-box warning for antidepressants in children? $\mathrm{N}$ Engl $\mathrm{J}$ Med. 2004; 351:1595-1598.

13. Electronic Medicine Compendium. Fluoxetine 20mg Hard capsules $<$ https://www.medicines.org.uk/emc/product/3131/smpc $>$. Accessed 27/09/. 2019.

14. Hiemke C, Hartter S. Pharmacokinetics of selective serotonin reuptake inhibitors. Pharmacol Ther. 2000; 85:11-28.

15. Poznanski EO, Grossman JA, Buchsbaum Y, Banegas M, Freeman L, Gibbons R. Preliminary studies of the reliability and validity of the children's depression rating scale. J Am Acad Child Psychiatry. 1984; 23:191-197. 
16. Busner J, Targum SD. The clinical global impressions scale: Applying a research tool in clinical practice. Psychiatry (Edgmont). 2007; 4:28-37.

17. Higgins JP, Altman DG, Gotzsche PC, et al. The cochrane collaboration's tool for assessing risk of bias in randomised trials. BMJ. 2011; 343:d5928.

18. The Nordic Cochrane Centre, The Cochrane Collaboration. Review Manager (RevMan). 2014; .

19. Egger M, Smith GD, Altman DG. Systematic Reviews in Health Care : MetaAnalysis in Context. 2nd ed. London: BMJ Books, 2001.

20. Higgins JP, Thompson SG. Quantifying heterogeneity in a meta-analysis. Stat Med. 2002; 21:1539-1558.

21. Atkinson SD, Prakash A, Zhang Q, et al. A double-blind efficacy and safety study of duloxetine flexible dosing in children and adolescents with major depressive disorder. J Child Adolesc Psychopharmacol. 2014; 24:180-189.

22. Lilly and Company. Fluoxetine Hydrochloride Clinical Study Summary: Study B1Y-MC-HCCJ <http://art45-paediatric-studiesdocs.ema.europa.eu/GROUP\%20F/Fluoxetine/fluoxetine\%20B1Y-MCHCCJ\%20Clinical\%20Study\%20Summary.pdf>. 2004.

23. Emslie GJ, Rush AJ, Weinberg WA, et al. A double-blind, randomized, placebo-controlled trial of fluoxetine in children and adolescents with depression. Arch Gen Psychiatry. 1997; 54:1031-1037. 
24. Emslie GJ, Heiligenstein JH, Wagner KD, et al. Fluoxetine for acute treatment of depression in children and adolescents: A placebo-controlled, randomized clinical trial. J Am Acad Child Adolesc Psychiatry. 2002; 41:12051215.

25. Emslie GJ, Prakash A, Zhang Q, Pangallo BA, Bangs ME, March JS. A double-blind efficacy and safety study of duloxetine fixed doses in children and adolescents with major depressive disorder. J Child Adolesc Psychopharmacol. 2014; 24:170-179.

26. March J, Silva S, Petrycki S, et al. Fluoxetine, cognitive-behavioral therapy, and their combination for adolescents with depression: Treatment for adolescents with depression study (TADS) randomized controlled trial. JAMA. $2004 ; 292: 807-820$.

27. Weihs KL, Murphy W, Abbas R, et al. Desvenlafaxine versus placebo in a fluoxetine-referenced study of children and adolescents with major depressive disorder. J Child Adolesc Psychopharmacol. 2018; 28:36-46.

28. Steel Z, Marnane C, Iranpour C, et al. The global prevalence of common mental disorders: A systematic review and meta-analysis 1980-2013. Int J Epidemiol. 2014; 43:476-493.

29. Ignaszewski MJ, Waslick B. Update on randomized placebo-controlled trials in the past decade for treatment of major depressive disorder in child and adolescent patients: A systematic review. J Child Adolesc Psychopharmacol. 2018; . 
30. Usala T, Clavenna A, Zuddas A, Bonati M. Randomised controlled trials of selective serotonin reuptake inhibitors in treating depression in children and adolescents: A systematic review and meta-analysis. Eur Neuropsychopharmacol. 2008; 18:62-73.

31. Tsapakis EM, Soldani F, Tondo L, Baldessarini RJ. Efficacy of antidepressants in juvenile depression: Meta-analysis. Br J Psychiatry. 2008; 193:10-17.

32. Courtney DB. Selective serotonin reuptake inhibitor and venlafaxine use in children and adolescents with major depressive disorder: A systematic review of published randomized controlled trials. Can J Psychiatry. 2004; 49:557-563.

33. Hetrick SE, McKenzie JE, Cox GR, Simmons MB, Merry SN. Newer generation antidepressants for depressive disorders in children and adolescents. Cochrane Database Syst Rev. 2012; 11:CD004851.

34. Cipriani A, Furukawa TA, Salanti G, et al. Comparative efficacy and acceptability of 21 antidepressant drugs for the acute treatment of adults with major depressive disorder: A systematic review and network meta-analysis. Lancet. 2018; 391:1357-1366.

35. Cipriani A, Zhou X, Del Giovane C, et al. Comparative efficacy and tolerability of antidepressants for major depressive disorder in children and adolescents: A network meta-analysis. Lancet. 2016; 388:881-890. 
Table 1 Randomized Controlled trials included in the meta-analysis

\begin{tabular}{|c|c|c|c|c|}
\hline Study & Design & $\begin{array}{l}\text { Duration } \\
\text { (weeks) }\end{array}$ & $\begin{array}{l}\text { Dose } \\
\text { range } \\
\text { (mg/day) }\end{array}$ & Population \\
\hline $\begin{array}{l}\text { Atkinson } \\
2014\end{array}$ & $\begin{array}{l}\text { Double blinded, } \\
\text { Placebo control }\end{array}$ & 10 & $\begin{array}{l}\text { Placebo } \\
\text { Flu 20-40 }\end{array}$ & $\begin{array}{l}103 \\
117\end{array}$ \\
\hline $\begin{array}{l}\text { B1Y-MC- } \\
\text { HCCJ }\end{array}$ & $\begin{array}{l}\text { Double blinded, } \\
\text { Placebo control }\end{array}$ & 6 & $\begin{array}{l}\text { Placebo } \\
\text { Flu 20-60 }\end{array}$ & $\begin{array}{l}21 \\
19\end{array}$ \\
\hline Emslie 1997 & $\begin{array}{l}\text { Double blinded, } \\
\text { Placebo control }\end{array}$ & 8 & $\begin{array}{l}\text { Placebo } \\
\text { Flu } 20\end{array}$ & $\begin{array}{l}48 \\
48\end{array}$ \\
\hline Emslie 2002 & $\begin{array}{l}\text { Double blinded, } \\
\text { Placebo control }\end{array}$ & 8 & $\begin{array}{l}\text { Placebo } \\
\text { Flu } 20\end{array}$ & $\begin{array}{l}109 \\
110\end{array}$ \\
\hline Emslie 2014 & $\begin{array}{l}\text { Double blinded, } \\
\text { Placebo control }\end{array}$ & 10 & $\begin{array}{l}\text { Placebo } \\
\text { Flu } 20\end{array}$ & $\begin{array}{l}117 \\
122\end{array}$ \\
\hline March 2004 & $\begin{array}{l}\text { Double blinded, } \\
\text { Placebo control }\end{array}$ & 6 & $\begin{array}{l}\text { Placebo } \\
\text { Flu } 20\end{array}$ & $\begin{array}{l}109 \\
112\end{array}$ \\
\hline Weihs 2018 & $\begin{array}{l}\text { Double blinded, } \\
\text { Placebo control }\end{array}$ & 8 & $\begin{array}{l}\text { Placebo } \\
\text { Flu } 20\end{array}$ & $\begin{array}{l}112 \\
112\end{array}$ \\
\hline
\end{tabular}

Flu: Fluoxetine 


\section{Figure Legends}

Figure 1: Prisma Flow chart for literature search results of fluoxetine versus placebo in major depressive disorder for children and adolescents.

Figure 2: Risk of bias summary and methodological quality graph: review authors' judgements about each risk of bias item for each included study and each methodological quality item presented as percentages across all included studies.

Figure 3: Efficacy outcomes measures for Fluoxetine versus placebo in the management of major depressive disorder for children and adolescents. A. Outcome: CDRS-R total score changes. B. CGI-S total score changes. C. CGI-I response rate. D. CDRS-R subscale - mood total score changes. E. CDRS-R subscale - somatic total score changes F. CDRS-R subscale - behavior total score changes CDRS-R: Children's Depression Rating Scale, Revised... CGI-S: Clinical Global Impressions - Severity. CGI-I: Clinical Global Impression scaleImprovement (CGI-I).

Figure 4: Tolerability and safety profile of fluoxetine compared to placebo. A. Outcome: Trial Withdrawal Due to adverse Event. B. Outcome: Total incidence of Side Effects. C. Outcome: Side Effect - Headache. D. Outcome: Side Effect Rash. 